\title{
INTERIM MEASURES IN THE CIVIL PROCEEDINGS IN ENGLAND: THE CONCEPT AND CERTAIN TYPES ${ }^{1}$
}

\author{
Valentina A. Koncheva \\ Peoples' Friendship University of Russia, Moscow, Russian Federation
}

Introduction: the legal institutions aimed at creating conditions for the efficiency of justice are now the subject of attention in the field of civil proceedings. This includes the institution of interim measures. The legal regulation of interim measures in the civil proceedings in England has been actively developing for several decades and today is of considerable interest to business, science and legal practice. The purpose of the research is to analyze the concept and features of the legal regulation of the main types of interim measures that can be of interest for forming the ideas about the possibilities of development of the Russian civil process. The obtained research results are based on the analysis of the normative provisions of Civil Procedure Rules 1998, the Senior Courts Act 1981, relating to the powers of the courts, the grounds and procedure for applying interim measures in the civil proceedings. The examples of judicial practice and the opinions of the researchers and practitioners are considered. The paper considers the general features of the legal institutions of interim measures in England and Russia and the peculiarities of understanding the legal possibilities of interim measures in the civil proceedings in England. Conclusions: the experience of England in solving the issues of ensuring the efficiency of civil remedies is of interest for both Russian legal science and practice. The study shows that there are specific features of the approach to the functioning of interim measures. This includes a fairly large amount of judicial discretion, a preliminary guarantee of compensation for the defendant's losses, and mostly voluntary enforcement of the court requirements. The legal experience of England may be of interest for discussing the ways to improve the domestic procedural regulation of interim measures.

Key words: interim measures, civil proceedings in England, anti-claim protection, Civil Procedure Rules 1998, court order, interim order, counterclaim, claim security.

Citation. Koncheva V.A. Interim Measures in the Civil Proceedings in England: the Concept and Certain Types. Legal Concept, 2020, vol. 19, no. 2, pp. 121-128. (in Russian). DOI: https://doi.org/10.15688/lc.jvolsu.2020.2.18 УДК $347.91 / 95$

Дата поступления статьи: 15.03.2020

ББК 67.410 .1 Дата принятия статьи: 03.04.2020

\section{ОБЕСПЕЧИТЕЛЬНЫЕ МЕРЫ В ГРАЖДАНСКОМ ПРОЦЕССЕ АНГЛИИ: ПОНЯТИЕ И ОТДЕЛЬНЫЕ ВИДЫ ${ }^{1}$ \\ Валентина Андреевна Кончева \\ Российский университет дружбы народов, г. Москва, Российская Федерация \\ Введение: правовые институты, направленные на создание условий эффективности правосудия, се- годня являются предметом внимания в области гражданского судопроизводства. В том числе это институт}


обеспечительных мер. Правовое регулирование обеспечительных мер в гражданском процессе Англии уже несколько десятилетий активно развивается и сегодня представляет значительный интерес со стороны бизнеca, науки и юридической практики. Целью исследования является анализ понятия и особенностей правового регулирования основных видов обеспечительных мер, способных вызывать интерес для формирования представлений о возможностях развития российского гражданского процесса. Полученные результаты исследования опираются на анализ нормативных положений Правил гражданского судопроизводства 1998 г., Закона о Высших судах 1981 г., относящихся к полномочиям судов, основаниям и порядку применения обеспечительных мер в гражданском процессе. Рассмотрены примеры судебной практики, мнения исследователей и практикующих специалистов. Рассматриваются общие черты правовых институтов обеспечительных мер в Англии и России и особенности понимания правовых возможностей обеспечительных мер в гражданском процессе Англии. Выводы: опыт Англии в решении вопросов обеспечения эффективности судебной защиты представляет интерес как для российской правовой науки, так и для практики. Исследование показывает наличие особенностей подхода к функционированию обеспечительных мер. В том числе это достаточно большие возможности судейского усмотрения, предварительное гарантирование обеспечения компенсации убытков ответчика и преимущественно добровольное исполнение требований суда. Правовой опыт Англии может представлять интерес для обсуждения путей совершенствования отечественного процессуального регулирования обеспечительных мер.

Ключевые слова: обеспечительные меры, гражданский процесс Англии, антиисковая защита, Правила гражданского судопроизводства 1998, судебный приказ, промежуточный приказ, встречное обеспечение, обеспечение иска.

Цитирование. Кончева В. А. Обеспечительные меры в гражданском процессе Англии: понятие и отдельные виды // Legal Concept = Правовая парадигма. -2020 . - Т. 19, № 2. - C. 121-128. - DOI: https://doi.org/ 10.15688/lc.jvolsu.2020.2.18

\section{Введение}

Вопросы современного развития и функционирования процессуальных институтов в мировой практике сегодня являются предметом пристального внимания исследователей в области гражданского судопроизводства. В числе правовых институтов, направленных на создание условий эффективности правосудия, в частности, рассматривается институт обеспечительных мер.

Обеспечительные меры в гражданском процессе представляют собой правовую категорию, предназначенную для гарантирования последующего исполнения судебных актов. Сущностью обеспечительных мер, как правило, является установление ограничения или запрета на совершение определенных судом действий, хотя возможно и возложение обязанностей в отдельных случаях, в таком виде этот правовой институт известен в российском законодательстве (ст. 140 ГПК РФ [7], ст. 91 АПК РФ [2]), в таком виде институт обеспечительных мер существует и в большинстве правовых систем мира. Вместе с тем исследователи и практикующие специалисты обращают внимание на наличие особенностей регулирования $[3 ; 4 ; 10 ; 18]$, представляющих интерес для изучения особенностей доктринального подхода к пониманию возможностей развития правового института обеспечительных мер. В этой связи большой интерес представляет процессуальное законодательство Англии.

Правовое регулирование мер обеспечения в гражданском судопроизводстве Англии уже несколько десятилетий находится в состоянии активного развития. Особенно, что достаточно важно, доктринальное развитие обеспечительных мер подвергается существенному воздействию со стороны судебной практики, которая, в свою очередь, интересна для оценки потребностей развития правовых институтов. Достаточно значимым критерием наличия интереса именно к английскому правовому опыту регулирования является факт, что нередко российские представители бизнес-сообщества предпочитают выбирать именно суды Англии для разрешения споров [1].

\section{Понятие и виды обеспечительных мер в гражданском процессе Англии}

Особенностью сложившейся в Англии правовой теории в рассматриваемом аспекте является, прежде всего, то, что в отношении 
судебных действий, которые входят в понятие обеспечительных мер, используются различные обозначения.

Это понятие «interim remedies», используемое в Правилах гражданского судопроизводства 1998 г. [12] (ч. 25) (далее - ПГС) и обозначающее категорию, в целом аналогичную обеспечению иска в российском законодательстве. Существует также понятие запрета «injunction», предусмотренное, например, в ч. 37 Закона о Высших судах 1981 г. [8], которое включает запреты на отчуждение и вывоз имущества, распоряжение о назначении управляющего имуществом и другие меры.

Несколько более узким по содержанию понятием является «interlocutory injunction», которое относится только к предварительным мерам защиты, в том числе досудебным. Этот запрет устанавливается как временное средство, имеющее оперативный характер, до установления обстоятельств дела. Отмечается, что это понятие относится также к праву справедливости [5]. Термин «interim injunctions» подразумевает промежуточный характер принудительных мер, направленных на обеспечение исполнения по иску [14, с. 103]. Содержанием судебных приказов может быть запрет на определенные действия, в том числе до обращения в суд, или требование прекращения какого-либо действия, восстановления положения (нужно обратить внимание: это именно процессуальный инструмент, то есть связанный с обращением в суд). В отношении промежуточных приказов применяются также термины: «interim measure», «ex parte injunction», то есть запрет, примененный без вызова сторон, в тех случаях, когда промедление нежелательно. Термин «final, perpetual injunction» обозначает окончательные меры, используемые при определении правомочности истца [11].

Отдельные разновидности судебных приказов могут быть охарактеризованы только в прямой связи с теми судебными делами, в которых были впервые применены. В том числе существует так называемый «запрет Марева» («Mareva injunction»), возникший как самостоятельный вид после судебного дела 1975 г. «Марева Компаниа Навиера СА» против «Интернэшнл Балккэриаз СА» [13]. Его содержанием является запрещение распоря- жения имуществом. Особенностью требований истца в данном случае должно быть обоснование высокой степени вероятности выигрыша им дела, а также невозможности последующего исполнения судебного решения. Этот приказ также называют «freezing order» [5]. Приказы Антона Пиллера («Anton Piller orders») также известны в связи с судебным делом. В данном случае это было дело Anton Piller KG v. Manufacturing Processes Ltd. (1976) [19], получившее широкую известность. Отмечается, что эти приказы нередко применяются в делах о защите авторских прав, интеллектуальной собственности и выдаются без вызова сторон [19]. По сути этот вид приказов похож на ордер на обыск, однако нужно обратить внимание, что допуск к имуществу обеспечивает сам ответчик. Учитывая существенный риск необоснованного вторжения в частное правовое пространство, при обращении о выдаче такого приказа истцу надлежит представить все аргументы касательно своей позиции, включая также данные об имеющихся возражениях со стороны ответчика.

Эти дела относились ко времени, когда правовое регулирование обеспечительных мер в Англии создавалось в том виде, как мы его знаем сегодня. Основной старт развитие современного правового регулирования получило в 1975 г., когда были сформулированы ведущие принципы обеспечительных мер. (В том числе широко известные сегодня правила об обоснованности позиции заявителя по делу с высокой вероятностью получения судебного решения в свою пользу, о соотношении потенциального вреда от применения обеспечительных мер и пользы для обеспечения исполнения судебного решения, о необходимости предоставления встречного обеспечения.) Аналогично предыдущим, можно назвать также более поздние судебные дела: Astro Exito Navegacion SA v. Southland Enterprise Co. Ltd (1983) [16], Cartier International AG \& Ors v. British Sky Broadcasting Ltd. \& Ors (2014) [17] и другие, которые послужили основанием для возникновения отдельных видов требований об обеспечении.

Достаточно большой интерес для развития российского правового регулирования в сфере процессуальных отношений имеет разновидность процессуальных запрещений, на- 
зываемая «Anti-suit injunction» (антиисковый запрет). Этот вариант процессуального запрещения направлен на устранение аналогичных судебных процессов, которые можно возбудить (или продолжить) в другом государстве. Данный вопрос тесно связан с категорией суверенитета (хотя требование относится только к участнику процесса, не к государству) и является абсолютно оправданным для применения в российских условиях с учетом существующего правового регулирования как обеспечительных мер, так и правил о порядке признания и исполнения решений иностранных судов и арбитражей в гражданском и арбитражном процессуальном праве. В.В. Ярков считает, что применение такой правовой конструкции не противоречит существующему регулированию и может быть полезным для отечественного процессуального права [15, с. 84-92]. В 2013 г. Президиумом ВАС был сделан вывод по материалам судебной практики, в котором фактически указано, что российское арбитражное процессуальное законодательство способно учитывать такие правовые конструкции [9, п. 32].

Рассмотренные понятия, используемые для обозначения обеспечительных мер в гражданском процессуальном законодательстве Англии, в своей основе подразумевают единую категорию: приказ. В ПГС в формулировке названия обеспечительных мер использован термин «order», то есть приказ. Это же обозначение используется в научной литературе, в частности, этот термин использует известный исследователь Н. Эндрюс [14, c. 434]. Единство используемой категории и правовой концепции позволяет рассматривать подобные судебные приказы и их разновидности как единый правовой институт обеспечительных мер.

\section{Особенности правового закрепления обеспечительных мер}

Обеспечительные меры в гражданском процессуальном праве Англии закреплены в различных правовых актах.

Прежде всего эти положения можно найти в ПГС. В этом нормативном акте обеспечительные меры находятся в части 25 , относящейся к регулированию процессуальных действий при рассмотрении дела судом первой инстанции. Процедура применения обеспечительных мер включает в себя обращение к суду, подтверждение обоснованности применения конкретных мер и нередко обеспечение убытков другой стороны. Вопрос о применении обеспечительных мер может быть решен как в закрытом порядке, без вызова стороны, так и с участием всех заинтересованных лиц. Меры, которые в соответствии с ПГС можно применять в качестве обеспечительных, указаны в виде открытого перечня, что не предусматривает ограничения суда в выборе других мер, как и в российском праве. В том числе такими мерами могут быть: временный запрет, приказ о проверке имущества, о проведении эксперимента на соответствующем имуществе, запрет на вывоз имущества, приказ о предоставлении информации и другие.

Особенностью регулирования относительно пределов правомочности суда является указание в нормах рассматриваемого источника только ограничений, относимых к наличию компетенции других судов. Суд вправе применить обеспечительные меры на любом этапе относительно судопроизводства: как при рассмотрении поданного иска, так и до его подачи (при необходимости), а также и после принятия судебного решения. Меры обеспечения принимаются, как правило, в связи с судопроизводством (поэтому нужно упомянуть о возможностях применения приказов на основе права справедливости, что расширяет пределы применения института обеспечительных мер). То есть правила относительно мер обеспечения включают достаточно большие возможности судейского усмотрения.

В статьях закона о Высших судах 1981 г. предусматриваемые меры в целом имеют подобный же характер. Суд вправе применить меры обеспечения на любом этапе судебного разбирательства, опираясь на понятия справедливости, обоснованности и баланса интересов сторон. Полномочия суда и свобода его усмотрения достаточно широки, они рассматриваются как закрепляющие права суда в области обеспечения справедливого разбирательства.

В целом относительно особенностей правового закрепления рассматриваемого инсти- 
тута нужно отметить, что процессуальная основа, целевая направленность и сущностная оценка обеспечительных мер в английской правовой системе имеют схожие черты с российским институтом обеспечительных мер в гражданском и арбитражном процессе. Безусловно, максимальная свобода судейского усмотрения относительно применения обеспечительных мер представляет собой значимую и заметную особенность, отличающую английское право и родственные ему правовые системы.

При общей схожести ряда характеристик на практике обращается внимание на следующие черты английского правового института обеспечительных мер: обеспечение убытков стороне, против которой применяются этих меры, гарантируется, что снимает значительную часть неудовлетворенности в обществе по поводу применения этих обеспечительных мер [6, с. 40-41]. Помимо этого, считаем необходимым обратить внимание на следующий достаточно значимый аспект: в большинстве случаев речь идет о самостоятельном совершении каких-либо действий ответчиком или иными лицами, которые имеют информацию о судебном приказе. Иное расценивается как неуважение к суду. То есть речь идет прежде всего не о принудительном исполнении даже с возможностью добровольного исполнения. В данном случае мы видим сложившийся подход к функционированию всего института обеспечительных мер. Это достаточно важный акцент, который касается роли суда в обществе и государстве. В данном случае такое положение косвенно подтверждается в том числе включением правоотношений в связи с исполнением требований суда в систему экономических взаимосвязей, - как подчеркивается специалистами, обычно исполнение указанных требований гарантируется за счет третьих лиц, в том числе банков, которые проверяют обязательность своих клиентов [6, с. 44-45]. Это очень важная характеристика правового регулирования института обеспечительных мер.

\section{Выводы}

Опыт решения отдельных вопросов в английском гражданском процессе уже дли- тельное время представляет большой интерес как для отечественной правовой науки, так и для практики. Внимание к английскому процессуальному законодательству относительно исследования правового регулирования обеспечительных мер обусловлено результативностью развития этого института, его признаваемой в мире эффективностью. Проведенное исследование показывает, что в английском гражданском процессе есть достаточно интересные особенности подхода к функционированию обеспечительных мер. Прежде всего представляют интерес характеристики, способствующие эффективности применения института, которые нашли отражение и в множестве возникших из практики форм, и в соотношении аспектов принуждения и добровольности при исполнении судебных требований. Зарубежный опыт, полученный в условиях другой правовой системы, системы прецедентного права, может представлять интерес для обсуждения путей совершенствования отечественного процессуального регулирования обеспечительных мер.

\section{ПРИМЕЧАНИЕ}

${ }^{1}$ Работа выполнена при финансовой поддержке гранта Президента РФ № НШ-2668-2020.6 «Национально-культурные и цифровые тренды социально-экономического и политико-правового развития Российской Федерации в XXI веке».

This work was financially supported by the Grant of the President of the Russian Federation No. HШ-2668-2020.6 "National-Cultural and Digital Trends in the Socio-Economic, Political and Legal Development of the Russian Federation in the $21^{\text {st }}$ Century".

\section{СПИСОК ЛИТЕРАТУРЫ}

1. Ануфриева, А. Сравнительный анализ законодательства и практики Англии, Казахстана и России по вопросам принятия мер по обеспечению иска / А. Ануфриева, Р. Д’Круз, Б. Тукулов. - Электрон. текстовые дан. - Режим доступа: https://online. zakon.kz/Document/?doc_id=31681154\#pos=3;-155 (дата обращения: 09.04.2020). - Загл. с экрана.

2. Арбитражный процессуальный кодекс Российской Федерации от 24.07.2002 № 95-Ф3 // Собрание законодательства РФ. - 2002. - 29 июля (№ 30). Ст. 3012. 
3. Башилов, Б. И. Основные тенденции правоприменительной практики рассмотрения споров, связанных с принятием обеспечительных мер по корпоративным спорам в арбитражном процессе / Б. И. Башилов // Сравнительно-правовые аспекты правоотношений гражданского оборота в современном мире : сб. ст. Междунар. науч.-практ. конф. памяти проф. В. К. Пучинского. - М. : Изд-во РУДН, 2018. - C. 42-49.

4. Безбах, В. В. Гражданский процесс зарубежных стран / В. В. Безбах, В. К. Пучинский. - М. : Зерцало-М, 2013. -519 с.

5. Белых, В. С. Договорное право Англии: сравнительно-правовое исследование / В. С. Белых. - М. : Проспект, 2017. - 208 с. - Электрон. текстовые дан. - Режим доступа: http://www. consultant. $\mathrm{ru} /$ cons/cgi/online.cgi?req $=$ doc $\&$ ts $=1136091350061$ $51216211607995 \&$ cacheid $=$ CFCDF6B90B963EB9D 3F95537F635984D\&mode $=$ splus \&base $=$ CMB\& $n=$ $18440 \& \mathrm{rnd}=0.2615022994456876 \#$ 1sjz0xq0tut (дата обращения: 10.04.2020). - Загл. с экрана.

6. Гландин, С. В. Основные виды обеспечительных мер по праву Англии и Уэльса / С. В. Гландин // Арбитражный и гражданский процесс. 2016. - № 9. - С. 40-45.

7. Гражданский процессуальный кодекс Российской Федерации от 14.11.2002 № 138-Ф3 // Собрание законодательства РФ. - 2002. - 18 нояб. (№ 46). - Ст. 4532.

8. Закон о Высших судах 1981 г. - Электрон. текстовые дан. - Режим доступа: https:/www. wipo.int/edocs/lexdocs/laws/en/gb/gb101en.pdf (дата обращения: 09.04.2020). - Загл. с экрана.

9. Информационное письмо Президиума Высшего Арбитражного Суда РФ от 09.07.2013 № 158 «Обзор практики рассмотрения арбитражными судами дел с участием иностранных лиц». Электрон. текстовые дан. - Режим доступа: http:// www.consultant.ru/cons/cgi/online.cgi?req=doc\&ts= $113609135006151216211607995 \&$ cacheid $=$ E $226195 F 96$ EB84106C3DD1E8167C3C93\&mode $=$ splus\&base $=$ LAW\&n=149878\&rnd $=0.2615022994456876$ \#cqoj0aj2uuo (дата обращения: 09.04.2020). - Загл. с экрана.

10. Иншакова, А. О. Реформа правовых основ международного коммерческого арбитража в Российской Федерации: анализ предпосылок и новелл / А. О. Иншакова // Культура. Наука. Интеграция. 2016. - № 3 (35). - С. 31-35.

11. Михайлов, А. Судебные приказы-запреты в английском праве / А. Михайлов. - Электрон. текстовые дан. - Режим доступа: https://blog.pravo.ru/ blog/5599.html (дата обращения: 10.04.2020). - Загл. с экрана.

12. Правила гражданского судопроизводства от 1998 (Civil Procedure Rules 1998). - Электрон. текстовые дан. - Режим доступа: https://www.justice. gov.uk/courts/procedure-rules/civil/rules/ (дата обращения: 10.04.2020). - Загл. с экрана.

13. Судебный запрет Марева. Оксфордский толковый словарь. - Электрон. текстовые дан. Режим доступа: https://investfuture.ru/dictionary/ word/sudebnyy-zapret-mareva (дата обращения: 09.04.2020). - Загл. с экрана.

14. Эндрюс, Н. Система гражданского процесса Англии: судебное разбирательство, медиация и арбитраж : пер. с англ. / Н. Эндрюс ; под ред. Р. М. Ходыкина ; Кембридж. ун-т. - М. : Инфотропик Медиа, 2012. -544 с.

15. Ярков, В. В. Применение антиисковых обеспечительных мер российскими судами: почему бы и нет? / В. В. Ярков // Закон. - 2014. - № 8. - С. 84-92.

16. Astro Exito Navegacion s.a. v. Southland Enterprise co. 1td. and nan jong iron and steel co. 1td. (the “messiniaki tolmi”) [1981] 2 Lloyd's Rep. 595. Electronic text data. - Mode of access: https://www.ilaw.com/ilaw/doc/view.htm?id=148077 (date of access: 10.04.2020). - Title from screen.

17. Cartier international ag v British sky broadcasting ltd. Reports of Patent Design and Trade Mark Cases. - July 2018. - No. 135 (7). - P. 475-500. DOI: $10.1093 / \mathrm{rpc} / \mathrm{rcy} 031$.

18. Doctrine in the modern world: legal traditions and modern potential / O. I. Miroshnichenko, T. M. Samusenko, Ya. V. Gaivoronskaya, E. E. Frolova//The Social Sciences. 2018. - Vol. 13, № 2.-P. 235-240.

19. What is an Anton Piller order? - Electronic text data. - Mode of access: https://legalvision.com.au/ anton-piller-orders-a-civil-search-warrant-2/ (date of access: 10.04.2020). - Title from screen.

\section{REFERENCES}

1. Anufriyeva A., D’Kruz R., Tukulov B. Sravnitelnyy analiz zakonodatelstva i praktiki Anglii. Kazakhstana $i$ Rossii po voprosam prinyatiya mer po obespecheniyu iska [Comparative Analysis of the Laws and Practices of England, Kazakhstan and Russia on the Adoption of Measures to Ensure the Claim]. URL: https://online.zakon.kz/Document/?doc_id= 31681154\#pos=3;-155 (accessed 09 April 2020).

2. Arbitrazhnyy protsessualnyy kodeks Rossiyskoy Federatsii ot 24.07.2002 № 95-FZ [Arbitration Procedure Code of the Russian Federation of 24.07.2002 no. 95-FZ]. Sobraniye zakonodatelstva $R F$ [Collection of Legislation of the Russian Federation], 2002, Jul. 29 (no. 30), art. 3012.

3. Bashilov B.I. Osnovnyye tendentsii pravoprimenitelnoy praktiki rassmotreniya sporov. svyazannykh s prinyatiyem obespechitelnykh mer po korporativnym sporam $\mathrm{v}$ arbitrazhnom protsesse [The Main Trends of Law Enforcement Practice in the 
Consideration of Disputes Related to the Adoption of Interim Measures for Corporate Disputes in the Arbitration Process]. Sravnitelno-pravovyye aspekty pravootnosheniy grazhdanskogo oborota $v$ sovremennom mire: sb. st. Mezhdunar. nauch.-prakt. konf. pamyati prof. V.K. Puchinskogo [Comparative Legal Aspects of Civil Relations in the Modern World Collection of Articles of the International Scientific and Practical Conference in Memory of Professor V.K. Puchinsky]. Moscow, Peoples' Friendship University of Russia, 2018, pp. 42-49.

4. Bezbakh V.V., Puchinskiy V.K. Grazhdanskiy protsess zarubezhnykh stran [Civil Process of Foreign Countries]. Moscow, Zertsalo-M Publ., 2013. 519 p.

5. Belykh V.S. Dogovornoye pravo Anglii: sravnitelno-pravovoye issledovaniye [Contract Law of England: Comparative Legal Study]. Moscow, Prospekt Publ., 2017. 208 p. URL: http://www. consultant.ru/cons/cgi/online.cgi?req=doc\&ts $=113609135006151216211607995 \&$ cacheid $=$ CFCD F6B90B963EB9D3F95537F635984D\&mode $=$ splus \&base $=$ CMB \&n $=18440 \& r n d=0.2615022$ 994456876\#1sjz0xq0tut (accessed 10 April 2020).

6. Glandin S.V. Osnovnyye vidy obespechitelnykh mer po pravu Anglii i Uelsa [The Main Types of Interim Measures Under the Law of England and Wales]. Arbitrazhnyy i grazhdanskiy protsess [Arbitration and Civil Proceedings], 2016, no. 9, pp. 40-45.

7. Grazhdanskiy protsessualnyy kodeks Rossiyskoy Federatsii ot 14.11.2002 № 138-FZ [Code of Civil Procedure of the Russian Federation of 14.11.2002 no. 138-Ф3]. Sobraniye zakonodatelstva $R F$ [Collection of Legislation of the Russian Federation], 2002, Nov. 18 (no. 46), art. 4532.

8. Zakon o Vysshikh sudakh 1981 g. [The Supreme Court Act 1981]. URL: https://www.wipo.int/ edocs/lexdocs/laws/en/gb/gb101en.pdf (accessed 09 April 2020).

9. Informatsionnoye pismo Prezidiuma Vysshego Arbitrazhnogo Suda RF ot 09.07.2013 № 158 «Obzor praktiki rassmotreniya arbitrazhnymi sudami del s uchastiyem inostrannykh lits» [Information Letter of the Presidium of the Supreme Arbitration Court of the Russian Federation of 09.07.2013 No. 158 "Review of the Practice of Consideration by Arbitration Courts of Cases Involving Foreign Persons"]. URL: http://www. consultant.ru/cons/cgi/online.cgi?req $=$ doc $\&$ ts $=1136$ $09135006151216211607995 \&$ cacheid $=\mathrm{E} 226195 \mathrm{~F} 96 \mathrm{E}$ B84106C3DD1E8167C3C93\&mode $=$ splus\&base $=$
$\mathrm{LAW} \& \mathrm{n}=149878 \& \mathrm{rnd}=0.2615022994456876$ \#cqoj0aj2uuo (accessed 09 April 2020).

10. Inshakova A.O. Reforma pravovykh osnov mezhdunarodnogo kommercheskogo arbitrazha $\mathrm{v}$ Rossiyskoy Federatsii: analiz predposylok i novell [Reform of the Legal Framework of International Commercial Arbitration in the Russian Federation: Analysis of Prerequisites and Novellas]. Kultura. Nauka. Integratsiya [Culture. The Science. Integration], 2016, no. 3 (35), pp. 31-35.

11. Mikhaylov A. Sudebnyye prikazy-zaprety v angliyskom prave [Court Orders-Prohibitions in English Law]. URL: https://blog.pravo.ru/blog/ 5599.html (accessed 10 April 2020).

12. Pravila grazhdanskogo sudoproizvodstva ot 1998 (Civil Procedure Rules 1998) [Civil Procedure Rules 1998]. URL: https://www.justice.gov.uk/ courts/procedure-rules/civil/rules/ (accessed 10 April 2020).

13. Sudebnyy zapret Mareva. Oksfordskiy tolkovyy slovar [Marev's Injunction. Oxford Explanatory Dictionary]. URL: https://investfuture.ru/ dictionary/word/sudebnyy-zapret-mareva (accessed 09April 2020).

14. Endryus N., Khodykin R.M., ed. Sistema grazhdanskogo protcessa Anglii: sudebnoe razbiratelstvo, mediatciia i arbitrazh [England Civil Procedure: Litigation, Mediation and Arbitration]. Moscow, Infotropik Media Publ., 2012. 544 p.

15. Yarkov V.V. Primeneniye antiiskovykh obespechitelnykh mer rossiyskimi sudami: pochemu by i net? [Application of Anti-Security Interim Measures by Russian Courts: Why Not?]. Zakon [Law], 2014, no. 8, pp. 84-92.

16. Astro Exito Navegacion s.a. v. Southland Enterprise co. ltd. and nan jong iron and steel co. ltd. (the "messiniaki tolmi") [1981] 2 Lloyd's Rep. 595. URL: https:/www.i-law.com/ilaw/doc/view.htm?id= 148077 (accessed 10 April 2020).

17. Cartier international ag $v$ British sky broadcasting ltd. Reports of Patent Design and Trade Mark Cases, July 2018, no. 135 (7), pp. 475-500. DOI: 10.1093/rpc/rcy031.

18. Miroshnichenko O.I., Samusenko T.M., Gaivoronskaya Ya.V., Frolova E.E. Doctrine in the modern world: legal traditions and modern potential. The Social Sciences, 2018, vol. 13, no. 2, pp. 235-240.

19. What is an Anton Piller order? URL: https:// legalvision.com.au/anton-piller-orders-a-civil-searchwarrant-2 (accessed 10 April 2020). 


\section{ПРОЦЕССУАЛЬНОЕ ПРАВО: ВОПРОСЫ ТЕОРИИ И ПРАВОПРИМЕНЕНИЯ}

\section{Information About the Author}

Valentina A. Koncheva, Candidate of Sciences (Jurisprudence), Senior Lecturer, Department of Civil Law and Procedure and Private International Law, Peoples' Friendship University of Russia, Miklukho-Maklaya St., 6, 117198 Moscow, Russian Federation, Koncheva-va@rudn.ru, https://orcid.org/0000-0002-9919-388X

\section{Информация об авторе}

Валентина Андреевна Кончева, кандидат юридических наук, старший преподаватель кафедры гражданского права и процесса и международного частного права, Российский университет дружбы народов, ул. Миклухо-Маклая, 6, 117198 г. Москва, Российская Федерация, Konchevava@rudn.ru, https://orcid.org/0000-0002-9919-388X 